\title{
TrkB Receptor Ligands Promote Activity-Dependent Inhibitory Synaptogenesis
}

\author{
Fredrick J. Seil, ${ }^{1,2,3}$ and Rosemarie Drake-Baumann ${ }^{1,2}$ \\ ${ }^{1}$ Neurology Research, Veterans Affairs Medical Center and Departments of ${ }^{2}$ Neurology and ${ }^{3}$ Cell and Developmental \\ Biology, Oregon Health Sciences University, Portland, Oregon 97201
}

\begin{abstract}
Organotypic cerebellar cultures derived from newborn mice were simultaneously exposed to activity-blocking agents and neurotrophins for 2 weeks. Activity-blocked explants treated with the TrkB receptor ligands BDNF and neurotrophin-4 (NT-4) developed a full complement of Purkinje cell inhibitory axosomatic synapses, as defined ultrastructurally, and displayed control spontaneous cortical discharge rates after recovery from activity blockade. Otherwise untreated activity-blocked cultures and activity-blocked cultures exposed to the TrkC receptor ligand NT-3 had reduced inhibitory synapse development and persistent cortical hyperactivity after recovery. The added TrkB receptor ligands did not induce axonal sprouting to account for increased inhibitory synaptogenesis. Addition of neurotrophins to untreated cerebellar cultures did not increase the complement of Purkinje cell axosomatic synapses. Exposure of cerebellar cul-
\end{abstract}

tures to a combination of antibodies to BDNF and NT-4 resulted in reduced inhibitory synapse formation, similar to the effects of activity blockade, indicating the necessity for endogenous neurotrophins for development of the full complement of inhibitory synapses in the presence of neuronal activity. Application of antibodies to BDNF and NT-4 to cerebellar explants exposed to picrotoxin to increase neuronal activity prevented the hyperinnervation of Purkinje cell somata by inhibitory terminals characteristic of cultures exposed to picrotoxin alone. These results are consistent with the concept that TrkB receptor ligands promote inhibitory synaptogenesis. The ability of neurotrophins to substitute for neuronal activity in encouraging development of inhibitory synapses may have therapeutic implications.

Key words: neurotrophins; neuronal activity; development; inhibitory synapses; cerebellar cultures; Purkinje cells
Consistent with earlier studies of effects of activity blockade in cultured CNS tissue (Ramakers et al., 1990; Baker and Ruijter, 1991; Furshpan, 1991; Ruijter et al., 1991; Corner and Ramakers, 1992), we reported a sustained increase of cortical spike discharges after transfer of newborn mouse-derived organotypic cerebellar cultures maintained in medium with tetrodotoxin (TTX) and elevated levels of $\mathrm{Mg}^{2+}$ to a physiological recording medium (Seil and Drake-Baumann, 1994). The increased activity correlated with ultrastructural findings of reduced numbers of inhibitory axosomatic and axodendritic synapse profiles on Purkinje cells, whereas numbers of excitatory parallel fiber-Purkinje cell dendritic spine synapse profiles remained at control levels. In contrast, cerebellar cultures continuously exposed to anti-GABA agents [picrotoxin (PTX) and bicuculline] that initially increased neuronal activity had a decreased rate of spontaneous cortical discharge after transfer to a physiological medium 2 weeks later, and the ratio of inhibitory axosomatic synapse profiles to Purkinje cell somatic profiles was twice that of control cultures (Seil et al., 1994a). Excitability of the circuitry in these cultures appeared to be regulated by activity-dependent effects on inhibitory (GABAergic) neurons or synapses.

In a study with postnatal rat dissociated visual cortex cultures containing GABAergic interneurons and target pyramidal cells (Rutherford et al., 1997), it was shown that activity blockade with TTX reduced the percentage of GABA-immunopositive neurons without affecting neuronal survival, whereas correlative electrophysiological studies indicated that GABA-mediated inhibition onto pyramidal neurons was decreased, with concomitant increases in pyramidal cell discharge rates. The effects of activity blockade were prevented by simultaneous exposure of the cultures to the

\footnotetext{
Received Jan. 13, 2000; revised April 19, 2000; accepted May 1, 2000.
}

This work was supported by the United States Department of Veterans Affairs. The technical assistance of Jennifer Jefferson, Marilyn Johnson, and Juany Rehling is gratefully acknowledged.

Correspondence should be addressed to Dr. Fredrick J. Seil, Neurology Research (P3-R\&D-35), Veterans Affairs Medical Center, Portland, OR 97201. E-mail: seilf@ ohsu.edu.

Copyright (C) 2000 Society for Neuroscience $0270-6474 / 00 / 205367-07 \$ 15.00 / 0$
TrkB receptor ligand brain-derived neurotrophic factor (BDNF) but not to the TrkA and TrkC receptor ligands nerve growth factor (NGF) and neurotrophin-3 (NT-3), suggesting to the authors that activity regulates cortical inhibition by regulation of BDNF. We subsequently reported in a brief communication (Seil, 1999) that application of BDNF and the other TrkB receptor ligand neurotrophin-4 (NT-4) to cerebellar cultures during activity blockade promoted development of the full complement of inhibitory axosomatic synapses on Purkinje cells, whereas application of NT-3 did not prevent the reduced formation of axosomatic synapses resulting from exposure to activity-blocking agents. Neither Purkinje cell survivability nor size were affected by neurotrophin application in this study, and the results were suggestive of BDNF and NT-4 having a role in the promotion of activity-dependent inhibitory synaptogenesis.

The purpose of the present series of experiments was to extend the study of the results of exogenous application of neurotrophins during activity blockade in cerebellar cultures by examining effects on cortical discharge rates and axonal sprouting, to define the role of endogenous neurotrophins in inhibitory synaptogenesis by application of neurotrophins to cultures in the presence of neuronal activity and by blocking their effect with anti-neurotrophin antibodies, and finally to determine whether increased inhibitory synapse formation consequent to picrotoxin-induced increased activity would be prevented by simultaneous exposure to anti-neurotrophin antibodies.

\section{MATERIALS AND METHODS}

Culture procedures. Organotypic cerebellar cultures were prepared from newborn (within $24 \mathrm{hr}$ after birth) Swiss-Webster mice (Harlan Sprague Dawley, Indianapolis, IN and Charles River Laboratories, Hollister, CA) by well established methods (Bornstein and Murray, 1958; Seil, 1979, 1993). The mice were cold-anesthetized and killed by exsanguination after an incision through the heart. After isolation of the cerebella under aseptic conditions and trimming of their lateral ends, each cerebellum was cross cut with scalpel blades into seven parasagittal sections 0.5-mm-thick. Each section was placed on a collagen-coated coverslip with a drop of nutrient medium, incorporated into a Maximow assembly, and incubated at 35.5$36^{\circ} \mathrm{C}$ in the lying-drop position. The nutrient medium was initially changed at $5 \mathrm{~d}$ in vitro (DIV) and twice weekly thereafter. Standard nutrient 
medium consisted of two parts $3 \mathrm{IU} / \mathrm{ml}$ low-zinc insulin (Squibb Institute for Medical Research, Princeton, NJ), one part 20\% dextrose, eight parts Eagle's minimum essential medium with Hanks' base and added L-glutamine, seven parts Simms' X-7 balanced salt solution (BSS) with sufficient incorporated HEPES buffer to make its concentration $10^{-2} \mathrm{M}$ in the fully constituted medium, and 12 parts fetal calf serum. For cultures chronically incubated with activity-blocking agents, $\mathrm{MgCl}_{2}$ and TTX (Sigma, St. Louis MO) dissolved in BSS buffered with HEPES were incorporated into the nutrient medium to final concentrations of $11.1 \mathrm{mM} \mathrm{Mg}{ }^{2+}$ and $10^{-8} \mathrm{M}$ TTX, concentrations that we had determined previously blocked all spontaneous cortical discharges (Seil and Drake-Baumann, 1994). A combination of TTX and high levels of $\mathrm{Mg}^{2+}$ was used to achieve complete blockade of Purkinje cell discharge because somatic electroresponsiveness is attributable to voltage-gated sodium conductance, whereas dendritic spikes are calcium-dependent (Llinás and Sugimori, 1980a,b). Neurotrophins, including BDNF (courtesy of Genentech, South San Francisco, CA; purchased from Alexis Corporation, San Diego, CA and Promega, Madison, WI), NT-3 (courtesy of Genentech and purchased from Alexis) and NT-4 (courtesy of Genentech and Regeneron, Tarrytown, NY; purchased from Alexis), were incorporated into the nutrient medium at concentrations of $25 \mathrm{ng} / \mathrm{ml}$ each, with or without the activity-blocking agents, and applied at explantation and at each of the subsequent feedings at 5, 9, and 12 DIV. Antibodies to BDNF and NT-4 (purchased from Promega) were incorporated together into standard nutrient medium at concentrations of $50 \mu \mathrm{g} / \mathrm{ml}$ each and applied to the cultures at explantation and during the subsequent feedings. PTX (Sigma) was incorporated into the nutrient medium at a $10^{-4} \mathrm{M}$ concentration and applied to the cultures at explantation and with each of the subsequent feedings, whereas some PTX-treated cultures were additionally and simultaneously exposed to antibodies to BDNF and NT-4, as described above, and also to greater antibody concentrations of $100 \mu \mathrm{g} / \mathrm{ml}$ each to determine whether the effect of antibody exposure could be increased with higher antibody levels in PTX-treated cultures.

Stain and immunocytochemical methods. Axonal sprouting was evaluated in silver-stained preparations and in culture preparations reacted with antibody to nonphosphorylated neurofilament protein (SMI 32; purchased from Sternberger Monoclonals, Baltimore, MD). In some cases, explants were processed for silver or neurofilament protein procedures after electrophysiological recording. Cultures for silver staining were fixed after 13-16 DIV as whole-mount preparations (total of 134) in 10\% formalin in BSS and processed by a Holmes silver method modified for tissue culture (Wolf, 1964). For immunocytochemistry, explants were fixed as wholemount preparations (total of 84 ) for $20 \mathrm{~min}$ at room temperature in $10 \%$ formalin in PBS, followed by $1 \mathrm{hr}$ in fresh PBS containing $0.5 \%$ Triton $\mathrm{X}-100$. After repeated washes with PBS, endogenous peroxide activity was blocked with $3 \% \mathrm{H}_{2} \mathrm{O}_{2}$ in methanol for $20 \mathrm{~min}$. The cultures were then incubated for $2-4 \mathrm{~d}$ at $10^{\circ} \mathrm{C}$ in a 1:2000 dilution of antibody in PBS with $1 \%$ rabbit carrier serum. They were subsequently exposed overnight to a 1:40 dilution of rabbit anti-mouse IgG in PBS-carrier serum, followed by a $4 \mathrm{hr}$ incubation in mouse peroxidase-antiperoxidase complex in PBS-carrier serum at room temperature (Sternberger et al., 1970). The last step was a 15-30 min incubation in a fresh diaminobenzidine-peroxidase mixture.

Electron microscopy. Cultures for ultrastructural examination were fixed at $15 \mathrm{DIV}$ in a mixture of glutaraldehyde $(1.5 \%)$ and paraformaldehyde $(1.5 \%)$ in cold cacodylate buffer $(0.1 \mathrm{M})$ supplemented with $0.05 \mathrm{M}$ sucrose and $2.25 \mathrm{mM} \mathrm{CaCl}_{2}$ (osmolarity between 650 and $750 \mathrm{mOsm}$, $\mathrm{pH}$ adjusted to 7.4), as described previously (Blank et al., 1982; Seil and DrakeBaumann, 1994). They were post-fixed in cacodylate-buffered $2 \%$ osmium tetroxide, dehydrated in a series of cold-graded ethanol and polymerized in LR white resin (London Resin Co., Reading Berkshire, UK). Thick sections were stained with toluidine blue and scanned by light microscopy. Thin sections were stained with uranyl acetate and lead citrate and examined with a Zeiss (Oberkochen, Germany) EM 10C electron microscope. Purkinje cell axosomatic synapse profiles, whose presynaptic elements are either basket cell axon terminals or Purkinje cell recurrent axon collateral terminals, both inhibitory (Palay and Chan-Palay, 1974), were identified and counted in Purkinje cell sections that included nucleus (only one section per cell was counted) at magnifications from 6000 to $10,000 \times$, and ratios of synapse profiles to soma profiles (not absolute synapse numbers) were determined. Synapse profiles were counted only if they included presynaptic and postsynaptic membrane thickenings and aggregates of synaptic vesicles. Data collection was restricted to axosomatic synapses, because these could be expressed as a ratio to Purkinje cell somata rather than in absolute numbers or in numbers per given cortical area. We did show previously, however, that activity blockade also reduces development of inhibitory axodendritic cortical synapses in cerebellar cultures but does not affect excitatory axospinous synapse development (Seil and DrakeBaumann, 1994), so that neurotrophin effects on axosomatic inhibitory synapses might reasonably be expected to be reflected on axodendritic inhibitory synapses as well. Because the more potent inhibitory synapses are those closest to the axon hillock in which Purkinje cell axonal spikes originate (Palay and Chan-Palay, 1974; Vincent and Marty, 1996), correlations of functional properties, such as spontaneous cortical discharge rate, with the density of axosomatic synapses would be expected to be close, as has been the case in previous studies (Seil and Drake-Baumann, 1994; Seil et al., 1994a). Synapse/soma profile ratios from the various experimental conditions were processed by one-way ANOVA, followed by
Table 1. Ratio of axosomatic synapse profiles to Purkinje cell somatic profiles in control, activity-blocked, and neurotrophin-treated activityblocked organotypic cerebellar cultures

\begin{tabular}{llll} 
Cultures & $\begin{array}{l}\text { No. of cell } \\
\text { profiles }\end{array}$ & $\begin{array}{l}\text { No. of } \\
\text { synapse } \\
\text { profiles }\end{array}$ & $\begin{array}{l}\text { Mean } \pm \text { SEM ratio } \\
\text { of synapse to cell } \\
\text { profiles }\end{array}$ \\
\hline Control $(n=10)$ & 103 & 228 & $2.21 \pm 0.13$ \\
$\mathrm{Mg}^{2+} /$ TTX $(n=10)$ & 102 & 127 & $1.25 \pm 0.10$ \\
$\mathrm{Mg}^{2+} /$ TTX/BDNF $(n=11)$ & 102 & 235 & $2.30 \pm 0.14$ \\
Control $(n=11)$ & 100 & 200 & $2.00 \pm 0.14$ \\
$\mathrm{Mg}^{2+} /$ TTX $(n=12)$ & 101 & 104 & $1.03 \pm 0.11$ \\
$\mathrm{Mg}^{2+} /$ TTX/NT-3 $(n=11)$ & 103 & 107 & $1.04 \pm 0.11$ \\
$\mathrm{Control}(n=10)_{\mathrm{Mg}^{2+} / \mathrm{TTX}(n=11)}(n)$ & 100 & 215 & $2.15 \pm 0.13$ \\
$\mathrm{Mg}^{2+} / \mathrm{TTX} / \mathrm{NT}-4(n=11)$ & 104 & 121 & $1.21 \pm 0.11$ \\
\hline $\mathrm{Com}^{2}(n)$ & 209 & $2.01 \pm 0.12$
\end{tabular}

Control and untreated activity-blocked cerebellar explants from the same culture set-ups as neurotrophin-treated activity-blocked cultures were compared at 15 DIV. $n$ is the number of cerebellar cultures from which the data were obtained. One-way ANOVA followed by the Tukey HSD multiple comparisons test indicates the following. (1) The axosomatic synapse profile to Purkinje cell soma profile ratio in untreated activity-blocked cultures $\left(\mathrm{Mg}^{2+} / \mathrm{TTX}\right)$ is significantly different from the ratios for control and BDNF-treated activity-blocked $\left(\mathrm{Mg}^{2+} / \mathrm{TTX} / \mathrm{BDNF}\right)$ cultures $(p<0.001$ in both cases), whereas there is no significant difference between control and BDNFtreated activity-blocked explants $(p=0.865)$. (2) The synapse profile to cell profile ratio in control cultures is significantly different from the ratios for untreated activityblocked $\left(\mathrm{Mg}^{2+} / \mathrm{TTX}\right)$ and NT-3-treated activity-blocked $\left(\mathrm{Mg}^{2+} / \mathrm{TTX} / \mathrm{NT}-3\right)$ cultures $(p<0.001$ in both cases), whereas there is no significant difference between untreated activity-blocked and NT-3-treated activity-blocked explants $(p=0.998)$. (3) The axosomatic synapse profile to cell soma profile ratio in untreated activity-blocked cultures $\left(\mathrm{Mg}^{2+} / \mathrm{TTX}\right)$ is significantly different from the ratios for control and NT-4treated activity-blocked $\left(\mathrm{Mg}^{2+} / \mathrm{TTX} / \mathrm{NT}-4\right)$ cultures $(p<0.001$ in both cases), whereas there is no significant difference between the ratios for control and NT-4treated activity-blocked cerebellar explants $(p=0.680)$.

the Tukey highly significant difference (HSD) multiple comparisons test using Systat software (SPSS, Chicago IL). $p \leq 0.05$ was considered statistically significant.

Electrophysiology. Extracellular electrophysiological recording procedures were as described previously (Leiman and Seil, 1973; Seil and Drake-Baumann, 1994; Seil et al., 1994a). Cultures were transferred after 13-16 DIV from the Maximow assemblies to a tissue chamber mounted on the stage of an inverted Zeiss Axiovert microscope. The nutrient medium was replaced with BSS additionally buffered with $1.5 \times 10^{-2} \mathrm{M} \mathrm{HEPES}$. Etched tungsten microelectrodes with tip diameters $<1 \mu \mathrm{m}$ were placed in cortical regions of the explants, and electrical activity was recorded at room temperature by means of a Grass Instruments (Quincy, MA) P15 preamplifier. Traces were monitored on an oscilloscope screen (Tektronix, Beaverton, OR), digitized (PCM-2; Medical Systems, Greenvale, NY), and stored on videotape (VCR; Panasonic, Secaucus, NJ) for subsequent retrieval and examination. Recordings were analyzed with a 486-IBM type computer with a 1401-plus CED interface and Spike 2 software (Cambridge Electronic Design, Cambridge, UK). Single-unit discharge rates were derived using the spike recognition features of Spike 2 software. Only spikes exceeding a signal-to-noise ratio of 2 were counted. The firing rate after recovery from activity blockade of each group of explants, with or without neurotrophin treatment, was averaged and compared with that of sister control cultures. Statistical differences between groups of data were determined using one-way ANOVA, followed by the Tukey HSD test for multiple comparisons.

\section{RESULTS}

\section{BDNF and NT-4 promote inhibitory synaptogenesis in the absence of neuronal activity}

Our expanded data on the results of exogenous application of neurotrophins to activity-blocked cerebellar cultures are presented in Table 1, which incorporates the data reported previously in a brief communication (Seil, 1999). Approximately half of the control numbers of Purkinje cell axosomatic synapse profiles were present in cerebellar cultures after $15 \mathrm{~d}$ of activity blockade, consistent with our previously reported results (Seil and DrakeBaumann, 1994). Cultures exposed to BDNF or NT-4 during activity blockade had axosomatic synapse profile to Purkinje cell somatic profile ratios comparable with those of control cultures, whereas exposure of activity-blocked cultures to NT-3 did not alter 

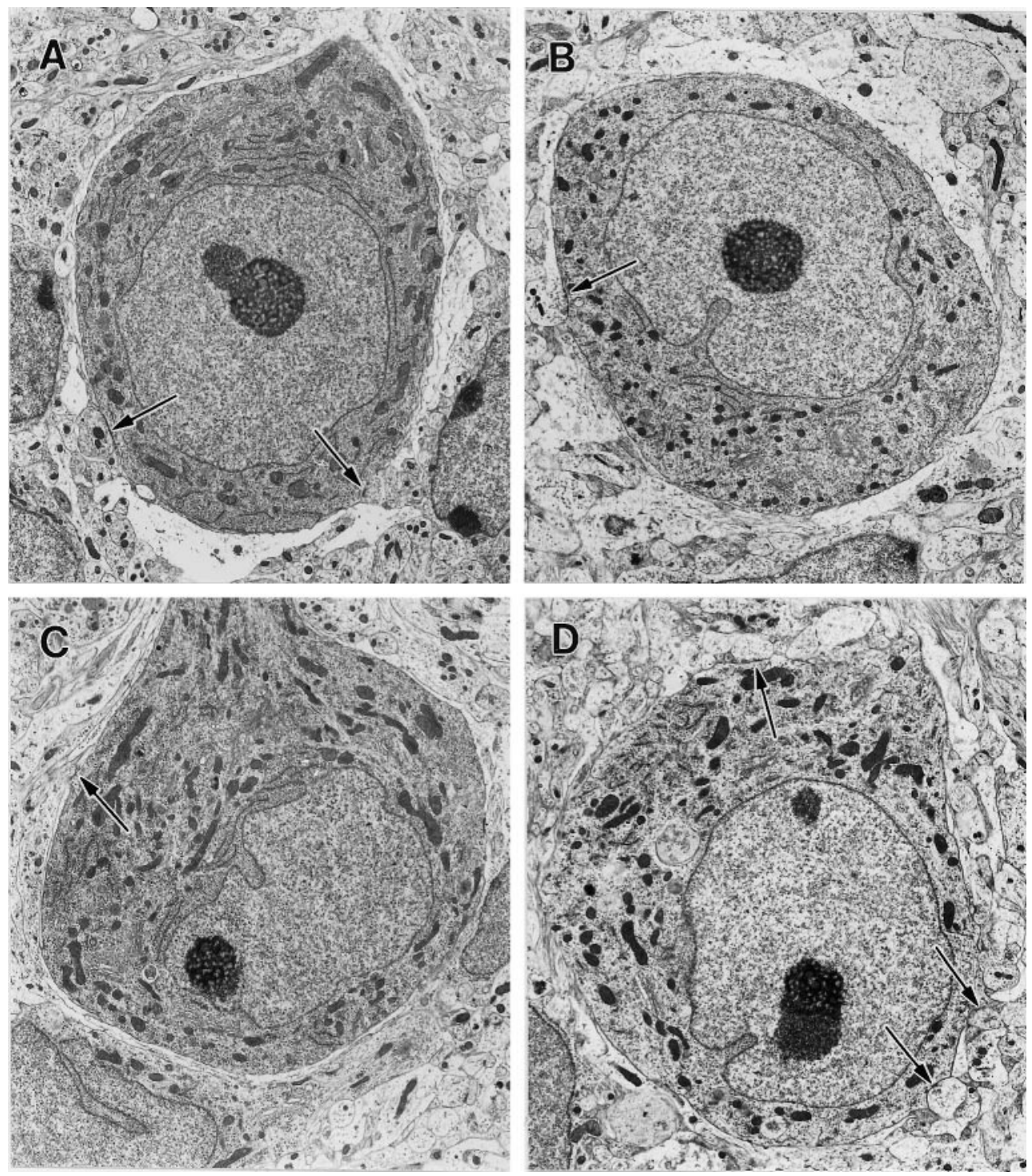

Figure 1. Electron micrographs of Purkinje cell soma profiles from control, activity-blocked, and neurotrophin-treated activity-blocked newborn mouse-derived organotypic cerebellar cultures at 15 DIV. All cells are shown at the same magnification $(3150 \times)$. The arrows indicate axosomatic synapse profiles. Astrocytic sheaths are evident as relatively clear areas around the circumferences of the cells. $A$, Purkinje cell from a control culture maintained in standard nutrient medium. $B$, Purkinje cell from a cerebellar explant continuously exposed to activity-blocking agents, $10^{-8} \mathrm{M}$ TTX and $11.1 \mathrm{~mm} \mathrm{Mg}^{2+}$, incorporated into the nutrient medium. $C$, Purkinje neuron from a cerebellar culture exposed since explantation to nutrient medium with incorporated activity-blocking agents and 25 ng/ml NT-3. $D$, Purkinje cell from a cerebellar explant continuously exposed to activity-blocking agents and $25 \mathrm{ng} / \mathrm{ml}$ NT-4. There are no significant differences in the morphology of the cells other than the ratios of axosomatic synapse to soma profiles, which are reduced in activityblocked cultures and activity-blocked cultures treated with NT-3, and at control levels in activity-blocked explants treated with TrkB receptor ligands (Table 1). the reduced development of axosomatic synapses that occurred in the absence of neuronal activity. Representative Purkinje cells from control, activity-blocked, and NT-3- and NT-4-treated activity-blocked cultures are shown at low magnification in Figure 1. Presynaptic elements of axosomatic synapse profiles were either basket cell axon terminals or Purkinje cell recurrent axon collateral terminals, as identified by established ultrastructural criteria (Palay and Chan-Palay, 1974; Seil and Drake-Baumann, 1994). There were no evident aberrant axon terminals in any of the culture groups and no differences in Purkinje cell somata among the various groups. Astrocytic ensheathment of Purkinje cells was also unaffected, by either activity blockade, as reported previously (Seil and Drake-Baumann, 1994), or addition of neurotrophins to activity-blocked explants.

\section{Axonal sprouting is not a factor in neurotrophin-promoted synaptogenesis}

Because neurotrophins have been reported to induce axonal sprouting that could result in formation of increased numbers of synapses (Mansour-Robaey et al., 1994; Cohen-Cory and Fraser, 1995; Rashid et al., 1995), overall neurite density was evaluated in silver stains, and Purkinje cell axonal sprouting was estimated in cultures reacted with antibody to nonphosphorylated neurofilament protein. We had demonstrated previously the sensitivity of the Holmes stain to neurite density in cerebellar cultures exposed to cytosine arabinoside after explantation in which increased neurite density attributable to axonal sprouting was dramatically evi- dent upon qualitative evaluation of silver-stained whole-mount culture preparations (Seil et al., 1980). No increase in neurite density was apparent qualitatively in any of the Holmes-stained preparations in the present study. Purkinje cell recurrent axon collaterals are the source of half of the presynaptic elements of Purkinje cell axosomatic synapses in cerebellar cultures (Seil and Drake-Baumann, 1994; Seil et al., 1994a), and Purkinje cells, their axons, and their target deep nucleus neurons are specifically stained in the reaction with nonphosphorylated neurofilament protein (Seil et al., 1994b). No recurrent axon collateral sprouting attributable to neurotrophin stimulation was evident in neurofilament-stained preparations, as shown by the representative Purkinje cells in Figure 2. Purkinje cells and portions of their axons and axon collaterals from an activity-blocked culture are illustrated in Figure $2 A$, whereas the activity-blocked Purkinje cells in Figure $2 B$ had been continuously exposed to BDNF. No differences were evident qualitatively in the axonal or axon collateral trees in the two conditions, nor were axons of activity-blocked Purkinje cells distinguishable from axons of Purkinje cells in untreated control cultures.

\section{Activity-blocked cultures exposed to BDNF and NT-4 have cortical discharge rates equivalent to control cultures}

The results of extracellular recordings of spontaneous cortical activity in cerebellar cultures are presented in Table 2. Although control cultures were immediately active after transfer to the buff- 


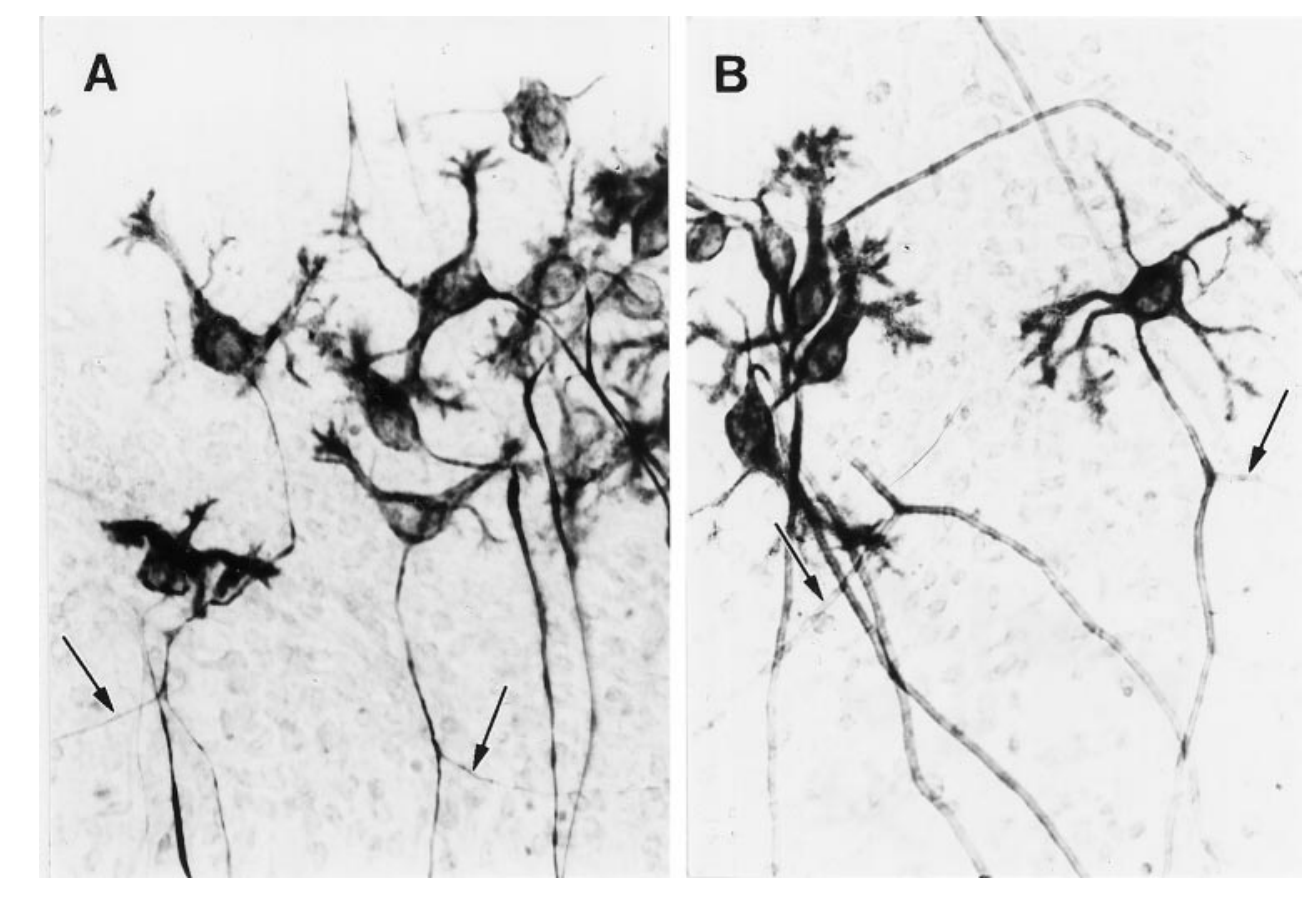

Figure 2. Whole-mount preparations of cerebellar cultures reacted at 15 DIV with antibody to nonphosphorylated neurofilament protein and processed by the peroxidase-antiperoxidase method (375x magnification). Purkinje cell recurrent axon collaterals are indicated by arrows. A, Purkinje cells from a culture continuously exposed to activity-blocking agents. $B$, Purkinje cells from an activity-blocked culture treated since explantation with BDNF, 25 $\mathrm{ng} / \mathrm{ml}$ nutrient medium. Axonal sprouting was not evident in neurotrophin-treated activity-blocked cultures.

Table 2. Spontaneous cortical discharge rates in control, activity-blocked, and neurotrophin-treated activity-blocked organotypic cerebellar cultures

\begin{tabular}{lll} 
Cultures & $\begin{array}{l}\text { No. of units } \\
\text { recorded }\end{array}$ & $\begin{array}{l}\text { Cortical spikes/sec } \\
\text { (mean } \pm \text { SEM) }\end{array}$ \\
\hline Control $(n=6)$ & 21 & $0.73 \pm 0.14$ \\
$\mathrm{Mg}^{2+} / \mathrm{TTX}(n=11)$ & 41 & $1.20 \pm 0.11$ \\
$\mathrm{Mg}^{2+} / \mathrm{TTX} / \mathrm{BDNF}(n=12)$ & 41 & $0.75 \pm 0.07$ \\
$\mathrm{Control}(n=9)$ & 25 & $0.61 \pm 0.06$ \\
$\mathrm{Mg}^{2+} / \mathrm{TTX}(n=11)$ & 46 & $1.39 \pm 0.14$ \\
$\mathrm{Mg}^{2+} / \mathrm{TTX} / \mathrm{NT}-3(n=10)$ & 34 & $1.48 \pm 0.23$ \\
$\mathrm{Control}(n=8)$ & 36 & $0.78 \pm 0.09$ \\
$\mathrm{Mg}^{2+} / \mathrm{TTX}(n=11)$ & 41 & $1.65 \pm 0.22$ \\
$\mathrm{Mg}^{2+} / \mathrm{TTX} / \mathrm{NT}-4(n=9)$ & 42 & $0.91 \pm 0.07$ \\
\hline
\end{tabular}

Cortical activity was recorded extracellulary from control, activity-blocked, and neurotrophin-treated activity-blocked cultures between 14 and 16 DIV. Activityblocked and neurotrophin-treated activity-blocked cultures were allowed to recover for at least $45 \mathrm{~min}$ before collection of data (see Materials and Methods). $n$ is the number of cerebellar cultures from which the data were obtained. One-way ANOVA followed by the Tukey HSD multiple comparisons test indicates the following. (1) The untreated activity-blocked cultures in all cases exhibited higher discharge rates than the controls ( $p=0.013, p=0.010$, and $p<0.001$, respectively). (2) The BDNF- or NT-4-treated activity-blocked cultures had cortical activity similar to controls and significantly different from the untreated activity-blocked cultures $(p=0.003$ and 0.002 , respectively). (3) The NT-3-treated activity-blocked cultures had discharge rates similar to the untreated activity-blocked group.

ered BSS recording medium, all activity-blocked cultures, whether simultaneously treated with neurotrophins or not, were electrically silent for at least $10 \mathrm{~min}$ after transfer. As reported previously (Seil and Drake-Baumann, 1994), untreated activity-blocked cultures began to discharge slowly after $10 \mathrm{~min}$, with a subsequent increase in discharge rates until they attained a state of continuous hyperactivity, often with spike bursts, $\sim 30 \mathrm{~min}$ after transfer to a medium without blocking agents. The spontaneous cortical discharge pattern of a control explant is illustrated in Figure $3 A$, and the hyperactive pattern of an otherwise untreated culture recovered from activity blockade is shown in Figure $3 B$. Activity-blocked cerebellar cultures continuously exposed to BDNF and NT-4 had cortical discharge rates comparable with control cultures (Table 2; Fig. $3 C$, which shows the cortical discharge pattern of a BDNFtreated culture after recovery from activity blockade), whereas activity-blocked cultures treated with NT-3 developed persistently
A

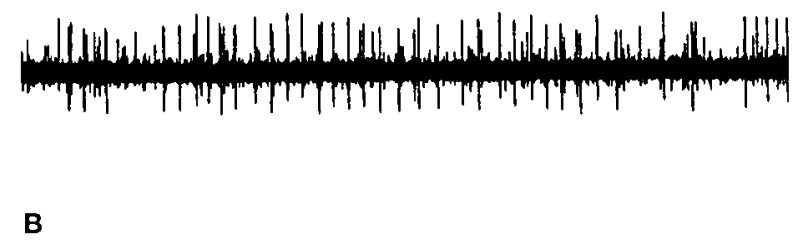

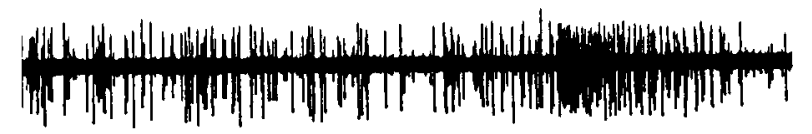

C

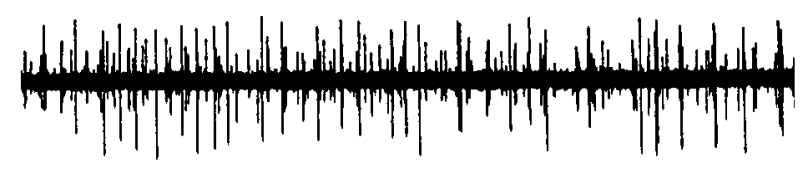

Figure 3. Extracellular records of spontaneous cortical activity in cerebellar cultures after 2 weeks in vitro. $A$, Untreated control explant recorded at 14 DIV. $B$, Increased activity with spike bursts in a cerebellar explant 40 min after recovery from activity blockade induced by continuous exposure to $10^{-8} \mathrm{M}$ TTX and $11.1 \mathrm{mM} \mathrm{Mg}^{2+}$. The culture had been silent during the first 10 min after transfer to a medium without activity-blocking agents, in contrast to control cultures, which were immediately active after transfer to a physiological recording medium. Recorded at 15 DIV. $C$, Cortical spikes recorded $45 \mathrm{~min}$ after transfer to a recording medium. The culture had been exposed to a combination of activity-blocking agents and BDNF $(25 \mathrm{ng} / \mathrm{ml}$ medium) for 15 DIV before recording. The spontaneous cortical activity pattern is similar to that of untreated control cultures. Time bar at the bottom, 5 sec.

hyperactive cortical discharge rates after recovery from activity blockade (Table 2). The cortical discharge patterns, which primarily represent Purkinje cell spikes (Seil and Drake-Baumann, 1994), correlated with the complement of Purkinje cell inhibitory axosomatic synapses, because control discharge rates were present in cultures with the full complement of inhibitory synapses, whereas cortical hyperactivity was evident in cultures with reduced inhibi- 
Table 3. Ratio of axosomatic synapse profiles to Purkinje cell somatic profiles in organotypic cerebellar cultures treated with neurotrophins, with a combination of antibodies to BDNF and NT-4 ( $\alpha$ BDNF/ $\alpha$ NT -4$)$, or with PTX with or without antibodies to BDNF and NT-4

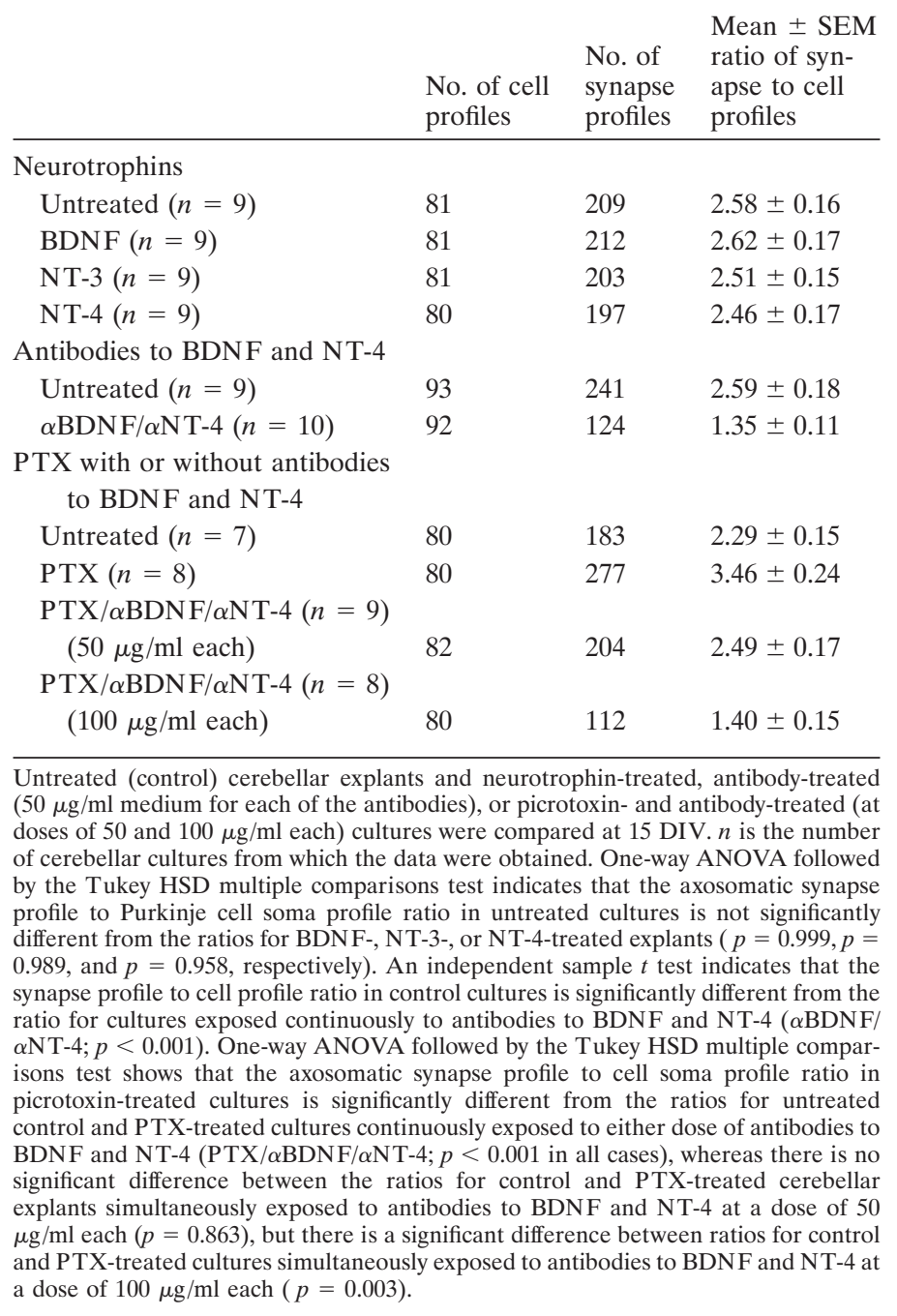

tion. The electrophysiological results were thus consistent with the morphological findings.

\section{Addition of neurotrophins to cultures in the presence of neuronal activity does not increase inhibitory synaptogenesis}

As shown in Table 3, exogenous application of neurotrophins in the presence of neuronal activity, by continuous exposure of otherwise untreated cerebellar cultures to the same concentrations of neurotrophins $(25 \mathrm{ng} / \mathrm{ml}$ medium) as in the experiments with activityblocking agents, did not induce an increase in inhibitory synaptogenesis. The ratio of Purkinje cell axosomatic synapse profiles to somatic profiles after exposure to any of the neurotrophins tested was not significantly different from that of untreated control explants. Addition of higher levels of neurotrophins to otherwise untreated explants remains to be tested. The control values for the mean ratios of synapse to cell profiles in this and the subsequent experiment with antibodies to neurotrophins (Table 3) are higher than in Table 1, possibly because of seasonal variations in donor mice, and for this reason specific controls are always set up with each individual experiment in studies with cultures.

\section{Blocking neurotrophins with antibodies reduces inhibitory synaptogenesis}

In initial experimental trials with antibody to BDNF, Purkinje cells in cultures exposed to $50 \mu \mathrm{g} / \mathrm{ml} \mathrm{BDNF} /$ nutrient medium had a ratio of $1.85 \pm 0.31$ (SEM) axosomatic synapse to soma profiles $(n=27)$ after 15 DIV compared with a ratio of $2.61 \pm 0.31$ for Purkinje cells in untreated control cultures $(n=31)$. In subsequent experiments, a combination of antibodies to BDNF and NT-4 (50 $\mu \mathrm{g} / \mathrm{ml}$ each) were applied to the cultures, with resultant reduction of the development of Purkinje cell axosomatic synapses to approximately half of the control value (Table 3), similar to the effect of activity blockade. The greater reduction of inhibitory synapse formation on Purkinje cell somata with the combination of antibodies to BDNF and NT-4 suggested that both TrkB receptor ligands contributed to the development of Purkinje cell inhibitory axosomatic synapses in cultures with neuronal activity.

\section{Antibodies to BDNF and NT-4 prevent increased inhibitory synapse formation in cultures exposed to PTX to increase neuronal activity}

Anti-BDNF plus anti-NT-4 antibody (50 $\mu \mathrm{g} / \mathrm{ml}$ medium each) treatment of organotypic cerebellar cultures simultaneously exposed to the anti-GABA agent PTX to increase neuronal activity prevented the increase in Purkinje cell axosomatic synapse development characteristic of cultured Purkinje cells chronically exposed to PTX (Seil et al., 1994a) (Table 3). However, the number of axosomatic synapse profiles was not reduced to the same degree as in cultures with background levels of neuronal activity (not exposed to PTX) (Table 3). To determine whether this was possibly because the quantity of antibody was not sufficient to bind all of the BDNF and NT-4 released as a result of PTX exposure, the antibody concentrations were doubled, with resultant reduction of the ratio of axosomatic synapse to Purkinje cell soma profiles to a value comparable with that of otherwise untreated cultures exposed to the lower antibody concentrations (Table 3). The prevention by anti-BDNF and anti-NT-4 antibodies of increased inhibitory synaptogenesis in response to exposure to an agent that induces accelerated Purkinje cell discharge, as well as the further reduction in synapse formation with increased concentrations of antibody, suggests that the increased inhibitory synaptogenesis is attributable at least in part to elevated levels of these neurotrophins in the presence of increased neuronal activity.

\section{DISCUSSION}

Evidence that neuronal activity is necessary for the full development and maintenance of inhibitory circuitry has been derived not only from investigations with tissue culture systems (Ramakers et al., 1990; Baker and Ruijter, 1991; Furshpan, 1991; Ruijter et al., 1991; Corner and Ramakers, 1992; Seil and Drake-Baumann, 1994; Seil et al., 1994a; Rutherford et al., 1997) but also from studies in vivo. Hendry and Jones (1986) reported markedly reduced GABA immunoreactivity in adult monkey visual cortex ocular dominance columns that had been deprived of input by enucleation of one eye. Monocular injection of TTX to prohibit retinal ganglion cell discharge achieved the same effect (Hendry and Jones, 1988). More recently, Benevento et al. (1995) recorded an increase in spontaneous activity in the visual cortex of dark-reared rats, correlating with a decrease in the number of GABA-reactive neurons. Micheva and Beaulieu (1995) described a significant reduction of GABAimmunopositive synapses in layer IV of the barrel field cortex of rats in which sensory deprivation was achieved by removal of whiskers soon after birth. This finding was consistent with an earlier report of increased spontaneous activity in the barrel field cortex of neonatally sensory-deprived animals (Simons and Land, 1987).

Neurotrophins have been reported to be synthesized and released in an activity-dependent manner (Zafra et al., 1991; Lindholm et al., 1994; Blöchl and Thoenen, 1995; Thoenen, 1995). These neurotrophic factors have also been reported to have functional effects at synapses (for review, see Schuman, 1999). BDNF enhanced synaptic currents in hippocampal cultures, an enhancement that was partially prevented by the "universal" Trk receptor inhibitor K252a (Kang and Schuman, 1995). BDNF and NT-3, but not NGF, enhanced synaptic strength at Schaffer collateral-CA1 
synapses in hippocampal slices from adult rats, an effect that was blocked by K252a (Levine et al., 1995). Hippocampal long-term potentiation (LTP) was reduced in CA1 of mutant mice that lacked BDNF (Korte et al., 1995), and treatment of hippocampal slices from BDNF knock-out mice with BDNF completely reversed deficits in LTP (Patterson et al., 1996).

Given an association between neuronal activity and the development and maintenance of inhibitory circuitry, activitydependent effects and neurotrophins, and neurotrophins and regulation of synaptic function, it seemed reasonable to consider the possibility that neurotrophins had a role in the development of inhibitory synapses. That this might, indeed, be the case was supported by the results of our study indicating that BDNF and NT-4 promoted the development of inhibitory Purkinje cell axosomatic synapses in cerebellar cultures in the absence of neuronal activity (Seil, 1999).

Support for this concept was strengthened by the results of the present study. Although it was evident from the previous report (Seil, 1999) that Purkinje cell survival and size were not significantly affected by either activity blockade or addition of neurotrophins to activity-blocked cultures, it was shown in the current work that neurotrophin-induced axonal sprouting was also not a significant contributory factor to the BDNF- and NT-4-promoted increase in Purkinje cell axosomatic synapses during activity blockade. Even if axonal sprouting had occurred, the axosomatic synapse regulatory function of the Purkinje cell astrocytic sheath would have had to have been overcome for hyperinnervation of Purkinje cell somata to develop (Seil et al., 1992; Seil, 1996). The only example of hyperinnervation of Purkinje cell somata by inhibitory axon terminals in the presence of intact astrocytic sheaths known to us occurred with continuous exposure of cerebellar cultures to agents that increased neuronal activity (Seil et al., 1994a).

Functional studies indicated a correlation with the morphological results. Activity-blocked Purkinje cells had reduced inhibitory axosomatic synapses and demonstrated persistent cortical hyperactivity after recovery from activity blockade. Purkinje cells treated with the TrkB receptor ligands BDNF or NT-4 during activity blockade developed the full complement of inhibitory axosomatic synapses and displayed cortical activity patterns in the control range after release from blockade. Spontaneous cortical discharge rates appeared to be inversely proportional to the complement of Purkinje cell axosomatic synapses, and activity blockade-induced reduction of Purkinje cell axosomatic synapse development was prevented by exogenous addition of TrkB receptor ligands, thus maintaining the functional integrity of the cortex. These studies also demonstrated the effectiveness of the activity blockade, with or without the presence of neurotrophins, for all cultures exposed to activity-blocking agents were electrically silent for at least $10 \mathrm{~min}$ after transfer to a physiological recording medium, even at maximum intervals after the last feeding, which was $4 \mathrm{~d}$.

Collectively, the results of this study indicate that TrkB receptor ligands have a role in the regulation of numbers of synapses, at least with regard to inhibitory synapses. Njå and Purves (1978) had reported previously that NGF increased the number of synapses on superior cervical ganglion neurons. More recently, Vicario-Abejon et al. (1998) described enhancement of the number of functional excitatory glutamatergic synapses by treatment of developing hippocampal cultures with BDNF and NT-3, although BDNF also promoted the formation of inhibitory synaptic connections. Our study was focused on inhibitory synapses because of our earlier finding of development of the full complement of excitatory axospinous cortical synapses in activity-blocked cerebellar cultures, although numbers of inhibitory synapses were markedly reduced (Seil and Drake-Baumann, 1994). Thus, inhibitory cortical synapses were obvious targets for studies of neurotrophin effects on activity-dependent synaptogenesis, but that is not to say that neurotrophins affect only inhibitory synapse development, as it appears otherwise from the literature.

The necessity for endogenous neurotrophins for development of the full complement of inhibitory synapses in the presence of neuronal activity was shown by the reduced formation of Purkinje cell axosomatic synapses when the TrkB receptor ligands were functionally blocked with antibodies. The reduction in inhibitory synapse development was similar to that consequent to activity blockade, which presumably reduces neurotrophin release (Blöchl and Thoenen, 1995; Thoenen, 1995) or reduces the responsiveness of neurons to neurotrophins (McAllister et al., 1999). The latter possibility is less likely because added exogenous neurotrophins can promote development of the full complement of inhibitory axosomatic synapses in the absence of neuronal activity (Seil, 1999). There may be a delicate balance, however, between levels of neuronal activity and responsiveness to or release of neurotrophins, because Purkinje cells discharging under control conditions failed to respond with increased axosomatic synapse development upon exogenous addition of the same levels of BDNF and NT-4 that promoted inhibitory synaptogenesis in activity-blocked cultures, an effect that could also be accounted for by a feedback mechanism that inhibited endogenous release in the presence of exogenously supplied neurotrophins. On the other hand, an increase in neuronal activity induced by PTX exposure resulted in hyperinnervation of Purkinje cell somata by inhibitory terminals, an effect that was mitigated by application of antibodies to the TrkB receptor ligands, which is consistent with the concept of accelerated neuronal activity inducing an increased release of neurotrophins, resulting in an increased development of inhibitory synapses. The activity state of the neuron may not only direct the release of neurotrophins but may also define the neurotrophin effect. Quantitative studies with varying concentrations of neurotrophins and levels of neuronal activity may provide some further insight into the nature of the complex interplay between neuronal activity and neurotrophin actions.

The fact that neurotrophins may substitute for neuronal activity in the promotion of synapse development does not necessarily mean that the effects of neuronal activity are mediated by neurotrophins. Regulation of the numbers of synapses may be only one of many aspects of neuronal activity-neurotrophin interaction during synapse development. Recently Cohen-Cory (1999) argued that BDNF modulates, but does not mediate, activity-dependent optic axon arborization because of a difference in mechanisms by which neurotrophins and neuronal activity regulate axonal arborization, with BDNF promoting axonal growth, whereas neuronal activity is involved with stabilization of axonal branching. Opportunities for such differences in mechanisms are probably greatly magnified in the complicated sequence of synaptogenesis, especially when the requirement for a balance between inhibition and excitation for proper circuit function is considered.

The ability of neurotrophins to achieve similar outcomes as neuronal activity may in some circumstances have therapeutic implications. Activity is known to promote functional recovery after CNS insults such as trauma or stroke, both in experimental and clinical situations (Jenkins and Merzenich, 1987; Chollet et al., 1991; Cohen et al., 1991; Elbert et al., 1994; Nudo et al., 1996; Johansson, 2000). Because activity appears to be necessary for the development (and probably restoration) of inhibitory circuitry, thus achieving an appropriate balance between excitation and inhibition and avoiding such negative consequences as seizures, it is conceivable that neurotrophin treatment might serve as an adjunct to such measures as physical therapy and perhaps as a substitute when use of activity-inducing measures is not possible. Such clinical considerations await development of more efficient methods of delivery of neurotrophins to appropriate CNS sites.

\section{REFERENCES}

Baker RE, Ruijter JM (1991) Chronic blockade of bioelectric activity in neonatal rat neocortex in vitro: physiological effects. Int J Dev Neurosci 9:321-329.

Benevento LA, Bakkum BW, Cohen RS (1995) Gamma-aminobutyric acid and somatostatin immunoreactivity in the visual cortex of normal and dark- reared rats. Brain Res 689:172-182.

Blank NK, Seil FJ, Herndon RM (1982) An ultrastructural study of cor- 
tical remodeling in cytosine arabinoside induced granuloprival cerebellum in tissue culture. Neuroscience 7:1509-1531.

Blöchl A, Thoenen H (1995) Characterization of nerve growth factor (NGF) release from hippocampal neurons: evidence for a constitutive and an unconventional sodium-dependent regulated pathway. Eur J Neurosci 7:1220-1228.

Bornstein MB, Murray MR (1958) Serial observations on patterns of growth, myelin formation, maintenance and degeneration in cultures of new-born rat and kitten cerebellum. J Biochem Biophys Cytol 4:499-504.

Chollet F, DiPiero V, Wise RJS, Brocks DJ, Dolan RJ, Frackowiak RSJ (1991) The functional anatomy of motor recovery after stroke in humans: a study with positron emission tomography. Ann Neurol 29:63-71.

Cohen LG, Bandinelli S, Findley TW, Hallett M (1991) Motor reorganization after upper limb amputation in man. Brain 114:615-627.

Cohen-Cory S (1999) BDNF modulates, but does not mediate, activitydependent branching and remodeling of optic axon arbors in vivo. J Neurosci 19:9996-10003.

Cohen-Cory S, Fraser S (1995) Effects of brain-derived neurotrophic factor on axon branching and remodeling in vivo. Nature 378:192-196.

Corner MA, Ramakers GJA (1992) Spontaneous firing as an epigenetic factor in brain development: physiological consequences of chronic tetrodotoxin and picrotoxin exposure on cultured rat neocortex neurons. Dev Brain Res 65:57-64.

Elbert T, Flor H, Birbaumer N, Knecht S, Hampson S, Larbig W, Taub E (1994) Extensive reorganization of the somatosensory cortex in adult humans after nervous system injury. NeuroReport 5:2593-2597.

Furshpan EJ (1991) Seizure-like activity in cell culture. Epilepsy Res 10:24-32.

Hendry SAC, Jones EG (1986) Reduction in number of immunostained GABAergic neurones in deprived-eye dominance columns of monkey area 17. Nature 320:750-753.

Hendry SAC, Jones EG (1988) Activity-dependent regulation of GABA expression in the visual cortex of adult monkeys. Neuron 1:701-712.

Jenkins WM, Merzenich MM (1987) Reorganization of neocortical representation after brain injury: a neurophysiological model of the bases of recovery from stroke. In: Neural regeneration, Progress in brain research, Vol 71 (Seil FJ, Herbert E, Carlson BM, eds), pp 249-266. Amsterdam: Elsevier.

Johansson BB (2000) Brain plasticity and stroke rehabilitation. Stroke 31:223-230.

Kang H, Schuman EM (1995) Long-lasting neurotrophin-induced enhancement of synaptic transmission in the adult hippocampus. Science 267:1658-1662.

Korte M, Carroll P, Wolf E, Brem G, Thoenen H, Bonhoeffer T (1995) Hippocampal long-term potentiation is impaired in mice lacking brainderived neurotrophic factor. Proc Natl Acad Sci USA 92:8856-8860.

Leiman AL, Seil FJ (1973) Spontaneous and evoked bioelectric activity in organized cerebellar tissue cultures. Exp Neurol 40:748-759.

Levine ES, Dreyfus CF, Black IR, Plummer MR (1995) Brain-derived neurotrophic factor rapidly enhances synaptic transmission in hippocampal neurons via postsynaptic tyrosine kinase receptors. Proc Natl Acad Sci USA 92:8074-8077.

Lindholm D, Castrén E, Berzaghi M, Blöchl A, Thoenen H (1994) Activity-dependent and hormonal regulation of neurotrophin mRNA levels in the brain: implications for neuronal plasticity. J Neurobiol 25:1362-1372.

Llinás R, Sugimori M (1980a) Electrophysiological properties of in vitro Purkinje cell somata in mammalian cerebellar slices. J Physiol (Lond) 305:171-195.

Llinás R, Sugimori M (1980b) Electrophysiological properties of in vitro Purkinje cell dendrites in mammalian cerebellar slices. J Physiol (Lond) 305:197-213.

Mansour-Robaey S, Clarke DB, Wang Y-C, Bray GM, Aguayo AJ (1994) Effects of ocular injury and administration of brain-derived neurotrophic factor on survival and regrowth of axotomized retinal ganglion cells. Proc Natl Acad Sci USA 91:1632-1636.

McAllister AC, Katz LC, Lo DC (1999) Neurotrophins and synaptic plasticity. Annu Rev Neurosci 22:295-318.

Micheva KD, Beaulieu C (1995) An anatomical substrate for experiencedependent plasticity of the rat barrel field cortex. Proc Natl Acad Sci USA 92:11834-11838.

Njå A, Purves D (1978) The effects of nerve growth factor and its anti- serum on synapses in the superior cervical ganglion of the guinea pig. J Physiol (Lond) 277:53-75.

Nudo RJ, Wise BM, SiFuentes F, Miliken GW (1996) Neural substrates for the effects of rehabilitative training on motor recovery after ischemic infarct. Science 272:1791-1794.

Palay S, Chan-Palay V (1974) Cerebellar cortex. Cytology and organization, pp 11-62, 180-215. New York: Springer.

Patterson SL, Abel T, Duel TAS, Martin KC, Rose JC, Kandel ER (1996) Recombinant BDNF rescues deficits in basal synaptic transmission and hippocampal LTP in BDNF knockout mice. Neuron 16:1137-1145.

Ramakers GJA, Corner MA, Habets AMMC (1990) Development in the absence of spontaneous bioelectric activity results in increased stereotype burst firing in cultures of dissociated cerebral cortex. Exp Brain Res 79:157-166.

Rashid K, Van der Zee CEEM, Ross GM, Chapman CA, Stanisz J, Riopelle RJ, Racine RJ, Fahnestock M (1995) A nerve growth factor peptide retards seizure development and inhibits neuronal sprouting in a rat model of epilepsy. Proc Natl Acad Sci USA 92:9495-9499.

Ruijter JM, Baker RE, DeJong BM, Romijn HJ (1991) Chronic blockade of bioelectric activity in neonatal rat cortex grown in vitro: morphological effects. Int J Dev Neurosci 9:331-338.

Rutherford LC, DeWan A, Lauer HM, Turrigiano GG (1997) Brainderived neurotrophic factor mediates the activity-dependent regulation of inhibition in neocortical cultures. J Neurosci 17:4527-4535.

Schuman E (1999) Neurotrophin regulation of synaptic activity. Curr Opin Neurobiol 9:105-109.

Seil FJ (1979) Cerebellum in tissue culture. In: Reviews of neuroscience, Vol 4 (Schneider DM, ed), pp 105-177. New York: Raven.

Seil FJ (1993) Organotypic neural cultures. In: In vitro biological systems: preparation and maintenance. Methods in toxicology, Vol 1 (Tyson CA, Frazier JM, eds), pp 7-26. Orlando, FL: Academic.

Seil FJ (1996) Neural plasticity in cerebellar cultures. Prog Neurobiol 50:533-556.

Seil FJ (1999) BDNF and NT-4, but not NT-3, promote development of inhibitory synapses in the absence of neuronal activity. Brain Res 818:561-564.

Seil FJ, Drake-Baumann R (1994) Reduced cortical inhibitory synaptogenesis in organotypic cultures developing in the absence of neuronal activity. J Comp Neurol 342:366-377.

Seil FJ, Leiman AL, Woodward WR (1980) Cytosine arabinoside effects on developing cerebellum in tissue culture. Brain Res 186:393-408.

Seil FJ, Drake-Baumann R, Herndon RM, Leiman AL (1992) Cytosine arabinoside effects in mouse cerebellar cultures in the presence of astrocytes. Neuroscience 51:149-158.

Seil FJ, Drake-Baumann R, Leiman AL, Herndon RM, Tiekotter KL (1994a) Morphological correlates of altered neuronal activity in organotypic cultures chronically exposed to anti-GABA agents. Dev Brain Res 77:123-132.

Seil FJ, Drake-Baumann R, Johnson ML (1994b) Dystrophic dendrites induced in cultured Purkinje cells by exposure to vinblastine. Brain Res 636:87-97.

Simons DJ, Land PW (1987) Early experience of tactile stimulation influences organization of somatic sensory cortex. Nature 326:694-697.

Sternberger LA, Hardy PH, Cuculis JJ, Meyer HG (1970) The unlabeled antibody enzyme method of immunohistochemistry. J Histochem Cytochem 18:315-333.

Thoenen H (1995) Neurotrophins and neuronal plasticity. Science 270:593-598.

Vicario-Abejon C, Collin C, McKay RDG, Segal M (1998) Neurotrophins induce formation of functional excitatory and inhibitory synapses between cultured hippocampal neurons. J Neurosci 18:7256-7271.

Vincent P, Marty A (1996) Fluctuations of inhibitory postsynaptic currents in Purkinje cells from rat cerebellar slices. J Physiol (Lond) 494:183-199.

Wolf MK (1964) Differentiation of neuronal types and synapses in myelinating cultures of mouse cerebellum. J Cell Biol 22:259-279.

Zafra F, Castrén H, Thoenen H, Lindholm D (1991) Interplay between glutamate and $\gamma$-aminobutyric acid transmitter systems in the physiological regulation of brain-derived neurotrophic factor and nerve growth factor synthesis in hippocampal neurons. Proc Natl Acad Sci USA 88: 10037-10041. 